Opinion in Microbiology

Manuscript Draft

Manuscript Number: COMICR-D-15-00068R1

Title: Motility in the epsilon-proteobacteria

Article Type: SI: 28 Growth\&Devel:Eukar/Prokar 2015

Corresponding Author: Dr. Morgan Beeby,

Corresponding Author's Institution: Imperial College London

First Author: Morgan Beeby

Order of Authors: Morgan Beeby

Abstract: The epsilon-proteobacteria are a widespread group of flagellated bacteria frequently associated with either animal digestive tracts or hydrothermal vents, with well-studied examples in the human pathogens of Helicobacter and Campylobacter genera. Flagellated motility is important to both pathogens and hydrothermal vent members, and a number of curious differences between the epsilon-proteobacterial and enteric bacterial motility paradigms make them worthy of further study. The epsilon-proteobacteria have evolved to swim at high speed and through viscous media that immobilize enterics, a phenotype that may be accounted for by the molecular architecture of the unusually large epsilonproteobacterial flagellar motor. This review summarizes what is known about epsilon-proteobacterial motility and focuses on a number of recent discoveries that rationalize the differences with enteric flagellar motility. 


\section{Motility in the epsilon-proteobacteria}

3 Morgan Beeby, ${ }^{\mathrm{a}, *}$

4

$5 \quad{ }^{\mathrm{a}}$ Department of Life Sciences, Imperial College London, South Kensington Campus, London, SW7 2AZ, UK.

$6 \quad$ Corresponding author: MB: email: mbeeby@imperial.ac.uk. Telephone: +44 (0) 207594 5251, Fax: +44

$7 \quad(0) 2075943057$ 
9 The epsilon-proteobacteriaare a widespread group of flagellated bacteria frequently associated with either

10 animal digestive tracts or hydrothermal vents, with well-studied examples in the human pathogens of

11 Helicobacter and Campylobacter genera. Flagellated motility is important to both pathogens and

12 hydrothermal vent members, and a number of curious differences between the epsilon-proteobacterial and

13 enteric bacterial motility paradigms make them worthy of further study. The epsilon-proteobacteriahave

14 evolved to swim at high speed and through viscous media that immobilize enterics, a phenotype that may be

15 accounted for by the molecular architecture of the unusually large epsilon-proteobacterialflagellar motor.

16 This review summarizes what is known about epsilon-proteobacterial motility and focuses on a number of

17 recent discoveries that rationalize the differences with enteric flagellar motility.

\section{Introduction}

19 Motile epsilon-proteobacteriaare found in diverse habitats, most commonly animal digestive tracts or

20 hydrothermal vents (Figure 1). Best studied are the animal digestive tract-associated species [1], prominently

21 the human gastrointestinal pathogens Campylobacterjejuniand Helicobacter pylori. C. jejuni and relatedspeciesare leading causes of gastroenteritis, yet often harmless commensals of birds [2]. Other members of order Campylobacteralesare also associated with mammalian intestinal tracts, including Wolinellasuccinogenes, a cattle rumen commensal [3], and pathogenic Arcobacterspecies [4]. Helicobacter species are invariably digestive tract-associated, with H.pylori colonizing $50 \%$ of humans on the planetand although associated with gastritis, gastric ulcers and gastric carcinoma, is also associated with beneficial outcomes with gastroesophageal reflux and asthma, indicating that the relationship between human host and H. pylori are more complex than first thought [5-7]. Similar observations of pathogenesis have been made for $H$. mustelaein the ferret gastrointestinal tract and H. felisin mice [8], and Helicobacter hepaticus causes chronic hepatitis, liver cancer and inflammatory bowel disease also in mice[9,10]. Yet despite numerous examples of digestive tract-associated epsilon-proteobacteria, there are also many environmental species. Many are chemolithotrophs[11] that obtain energy by oxidizing compounds found in their environment. The Sulfurospirillum, Sulfurimonas,Sulfuricurvum,Thiovulum, and some Arcobactergenera from the Campylobacteralesorder are environmental bacteria [12,13], with habitats ranging from marine 
hydrothermal vents and coastal sediments [14], underground oil-storage facilities [15], plant roots in salt marsh sediments [16] and pond mud [17]. Intriguingly, there are multiple cases of epsilon-proteobacteria that combine animal association with hydrothermal vent environments by establishing symbioses with gastropods and annelids endemic to vents $[18,19]$.

Flagellar motility is important to both pathogenic [2] and hydrothermal vent-associated [20] species. In animal-associated species, motility is critical for host colonization and virulence by enabling traversal through viscous gastrointestinal mucous [2,21]. Motility is also clearly important for environmental members of the epsilon-proteobacteria as demonstrated by high expression levels of flagellar genes in hydrothermal vent epsilon-proteobacteria [20,22]. In environmental Thiovulumspp., flagella play key roles in nutrient acquisition whereby cells attach to surfaces and rotate their flagella to increase oxygen and sulphide flux for metabolism [23].

Despite using homologous flagellar systems, there are striking differences between epsilon-proteobacterial and the enteric motility models Escherichia coli and Salmonella entericasv. Typhimurium. While enterics are often peritrichous (multiple flagella distributed over the cell body), the epsilon-proteobacteriahave one or a few polar flagella. And yet despite generally having fewer flagella, representative epsilon-proteobacteria swim faster than the enterics in low-viscosity media, and continue to swim at high speed even in highviscosity environments that immobilize the enterics[24-26]. This review highlights the unique features of epsilon-proteobacterial motility that may play a role in their unique range of habitats.

\section{Epsilon-proteobacterial swimming ability}

Characteristic of the epsilon-proteobacteria is their ability to swim rapidly, and to continue swimming even in high viscosity environments. C. jejuni [24] and H. pylori [26] are capable of swimming in viscous fluids that immobilize E. coli faster even than E. coli's fastest swimming speed. A number of observations suggest that this characteristic swimming may be a result of higher torque production than enteric bacteria. The torque of epsilon-proteobacterialflagellar swimming has been measured for $\mathrm{H}$. pylori, yielding an estimate of $3600 \mathrm{pN} \mathrm{nm} \mathrm{[27],} \mathrm{approximately} \mathrm{three} \mathrm{times} \mathrm{that} \mathrm{observed} \mathrm{in} \mathrm{E.} \mathrm{coli,} \mathrm{of} 1260 \mathrm{pN} \mathrm{nm} \mathrm{[28,29].} \mathrm{Observations}$ of Helicobacter felis shows swimming behavior capable of propelling the bacterium between tissues [30], and Thiovulummajus,despite being a giant $\sim 9 \mu \mathrm{m}$-diameter cell, is the second fastest-swimming bacterium 
studied to-date, capable of swimming at over $600 \mu \mathrm{m} / \mathrm{s}$ [25]. It is also thought that high torque and the largecell sizecontributes to self-organization of Thiovulumcells into 2D hexagonal lattices on surfaces which may contribute to increased nutrient flux [23]. Although other epsilon-proteobacteria have not been studied in similar detail, their ability to swimming through viscous media, and prevalent observations of rapid, darting motility, suggest similar mechanisms underly the characteristic swimming ability of all epsilonproteobacteria (Figure 1).

\section{Cell biology associated with motility}

Epsilon-proteobacteria are often slender spiral rods with polar flagella (Figure 1). Campylobacter species tend to be approximately $0.5 \mu \mathrm{m}$ wide and over $1 \mu \mathrm{m}$ long, while Helicobacter species can be up to $1 \mu \mathrm{m}$ wide and correspondingly longer.Although it has been suggested that $C$. jejuni'sswimming ability is partially a product of using its spiral shape for traction [31], rod-shaped H. pylori mutants swimming ability is unimpaired in both low and high viscosity media [32], suggesting that spiral shape may not be directly involved in motility. Deeper-branching epsilon proteobacteriaNautilia and Nitratiruptor are not spiral-shaped, but also have polar flagella [11,33]. Furthermore, Thiovulumspp. are also extremely fast swimmers despite being very large $(\sim 9 \mu \mathrm{m})$ ovoids with peritrichous flagella. Together these observations indicate that while helical cell shape may be involved in epsilon-proteobacterial motility, it is not an essential determinant.

Beside the possible contribution of cell shape to motility, Helicobacter species use other strategies that may enhance motility. $H$. pyloricolonizes the acidic mucous of the stomach, where acidity makes the mucous form a gel [27]. To survive and maintain motility, H. pylori secretes a urease which breaks down urea to form ammonium, raising local $\mathrm{pH}$, and reverting mucous to a viscous fluid. SomeHelicobacter species such as Helicobacter muridarum [34] and Helicobacter trogontum [35] also assemble distinctive helical periplasmic non-flagellar ribs within their periplasm. The significance of these ribs is unclear, but may further augment the spiral characteristics of these species, or reinforce cell shape in bacteria which may be exposed to large torques that might otherwise buckle or mishape the cell.

Correct cellular localization of flagella is important for full motility of the epsilon-proteobacteria. Flagellar localization and number are controlled by a GTPase, FlhF, and putative ATPase, FlhG, respectively [36]. Although the mechanism behind FlhF and FlhG function is unclear, they likely dictate the variations across 
the epsilon-proteobacteria (Figure 1), from a single motor at one pole (monotrichous), a single motor at each pole (amphitrichous), multiple motors at one pole (lophotrichous), to multiple motors at each pole.

Exceptions to polar localization are seen in Helicobacter mustelae [37], with occasional lateral flagella, and the hundreds of peritrichous flagella in Thiovulumspp. [38]. Electron cryo-tomography studies of $C$.

jejunipole morphology reveal a ribosome exclusion zone at flagellated poles [39] and a single polyphosphate storage granule beneath the flagellar motor. The significance of the ribosome exclusion zone and the storage granule are unclear, but they may be involved in aiding flagellar rotation.

\section{Epsilon-proteobacterial flagella}

The machine that drives motility in the epsilon-proteobacteria is from the same widespread family of machinery responsible for motility in two-thirds of bacteria: the bacterial flagellar motor $[29,40,41]$.

Flagellar motors drive rotation of a flexible $\sim 50 \mathrm{~nm}$-long hook that in turn rotates a multi-micron filament to coil to form a helical propeller. Flagellar motors consists of a $\sim 50 \mathrm{~nm}$-diameter cytoplasmic rotor, termed the C-ring, that is rotated by a peptidoglycan-anchored stator ring. The stator is composed of a number of Mot $A_{4} B_{2}$ stator complexes that couple proton flux to rotation of the C-ring, the mechanism for which is likely conservedacross bacteria [42]. The C-ring is attached to the rod, an axial driveshaft that traverses the periplasm, peptidoglycan and outer membrane where it attaches to the base of the hook. 'Navigation' is achieved in the epsilon-proteobacteria using the same chemoreceptor system as found in other bacteria, with minor variations; these are reviewed in reference [2].

As with peritrichous bacteria, epsilon-proteobacterialflagellar filaments are multimicron-long polymers of flagellin. Some epsilon-proteobacteria, notably the Helicobacter spp. envelope their flagella with outermembrane extensions called sheaths. In C. jejuniand H. pylori, two flagellins, FlaA and FlaB, form the filament. The major flagellinFlaA is essential, but the role of FlaB varies. Both flagellins have a divergent domain D1 compared to that found in Salmonella; D1 is involved in polymerization of the filament and D1 interactions are possibly substituted by O-linked glycosylation in epsilon-proteobacteria [2].Curiously, an outcome of this is that although the Salmonella flagellin polymerizes into a filament composed of 11 protofilaments, C. jejuniFlaA polymerizes into a seven-protofilament filament [43]. 
clear that the epsilon-proteobacterial motor is considerably more complex than the enteric paradigm (Figure

117 2). Previous studies have sporadically reported disk-like structures beneath the outer membrane of many epsilon-proteobacteria such as C. fetus [44], C. rectus [45], W. succinogenes [46], and environmental Arcobacter species [47], observations supported by purification of disks [48,49]. Recent work in C. jejunihas shown that the cell pole itself has a polar depression into which the hook attaches [39,40,50]. Electron cryotomography has revealed that the epsilon-proteobacterial motor is larger than the enteric motor, with a wider C-ring and multiple additional 'disk complex' components in the periplasm [40,51]. The wider C-ring is conserved across all epsilon-proteobacteria imaged to date. C. jejuni and H. hepaticus exhibit wider C-rings with diameter $53 \mathrm{~nm}$ [40], while the W. succinogenesC-ring appears approximately $\sim 60 \mathrm{~nm}$ wide in thinsection EM [48]. Inspection of this wider C-ring reveals an inner lobe that is elongated relative to that in Salmonella, suggestive of an additional domain or protein responsible for "spacing" the C-ring wider [51]. How do the epsilon-proteobacterial stator complexes maintain interaction with a C-ring that is wider than the enteric motor? In Salmonella, approximately 11 stator complexes interact with the peptidoglycan layer and P-ring [28,52,53], but $C$. jejuni has 17 stator complexes positioned at considerably wider diameter. This is also evident in both Helicobacter muridarumand Helicobacter felis, in which freeze-fracture studies revealed approximately 17 'studs' [30,34] previously shown to be stator complexes [54]. Thus in the epsilonproteobacteria imaged so far, additional stator complexes are positioned at a wider radius than in the enteric motor.

Taken together, the combination of a wider rotor ring and additional stator complexes presents a structural rational for the higher torque and characteristic motility of the epsilon-proteobacteria. Experiments in E. coli have shown that incorporation of additional stator components contribute force approximately independently to the torque of a motor [28]. With additional stators, it follows that the epsilon-proteobacterial motor must exert higher torque than the enteric motor. Furthermore, if the point of application of this force to the axial driveshart is from a greater radius (as it is in the epsilon-proteobacteria), the torque exerted by each stator complex will further scale proportionally, resulting in a high-torque motor. evident in the disk complex; the largest is a $~ 100 \mathrm{~nm}$-diameter basal disk immediately beneath the outer membrane $[10,40]$ attached to the conserved motor core, with two smaller disks closer to the inner 
membrane named the proximal and medial disks. Because the disk complex is required for stator complex incorporation into the motor it may be that its primary role is to act as a scaffold for correct positioning of the stator complexes upon assembly into the motor to enable continued stator:rotor interactions with a wider Cring. The significance of disk concavity in $C$. jejuniremainsunclear, particularly given that this characteristic is absent from Helicobacter spp. disks.

Disk complex components of the $C$. jejunimotor have been identified using transposon screens $[51,55,56]$. Using biochemical studies of each gene in combination with electron cryo-tomography, four proteins have been located within the $C$. jejunimotor, $f l g P$, flgQ, $p f l A$ and $p f l B$. Abundance, outer membrane localization, and imaging reveal that FlgP forms the basal disk, likely in complex with FlgQ. PflB forms an intermediary ring around the rod, whilePflA forms a wider ring above the outer membrane, and analysis of the location of the stators revealed that the stator complexes bind to the PflA ring. Five other proteins are additional candidates for further components of the $C$. jejunimotor [55]. FlgV, a transmembrane protein and CJJ81176_0996, are implicated in C-ring interaction, FlgW and FlgY, are implicated in flagellar type III secretion system interaction, and, FlgX is implicated in additional stator complex interactions. The structural roles of these proteins remain to be confirmed.

\section{Conclusions}

Epsilon-proteobacteriaswim rapidly and through high-viscosity environments. A number of factors may contribute to this characteristic motility, and recent studies suggested that a major factor is flagellar motors that produce higher torque than enteric bacteria. A number of key future questions will be important in the future to better understand epsilon-proteobacterial motility.

What was the selective benefit of swimming rapidly through viscous fluids that lead to evolution of epsilonproteobacterial motility? Although convenient to cite the benefits of burrowing through viscous mucous for pathogens, the prevalence of rapid motility across both environmental and pathogenic epsilon-proteobacteria suggests an ancient, pre-pathogenesis origin. Experiments aimed at understanding how environmental epsilonproteobacteria benefit from rapid motility may shed light on these questions. This raises another question, however: what was the selective benefit of a high-torque motor in ancestral epsilon-proteobacteria, and contemporary environmental strains? The presence of epsilon-proteobacteria in oilfields $[57,58]$ may be 
assisted by ability to swim through viscosities corresponding to Class A heavy oil (10 - $100 \mathrm{cP})$ which they biodegrade to form more viscous forms of oil. More information on the range of environments inhabited by epsilonproteobacteria may provide more data to understand these selective pressures, in turn contributing to understanding how the complex epsilonproteobacterialflagellar motor evolved.

Finally, little is known about the biophysics of the epsilonproteobacterialflagellar motor. Further work is necessary to accurately determine the torque of individual motors at high-loads in different species: does it consistently produce higher torque than the enteric motor? If not, how can we explain this in the context of a wider C-ring, additional stators, and standard proton motive force [59]? In E. coli, rotation of the flagellar motor is composed of 26 steps. With a wider C-ring, does the epsilon-proteobacterial motor also rotate with correspondingly more steps? Such insights may provide crucial additional information towards understanding universal mechanistic details of torque generation.

In sum these questions will add to our understanding of epsilonproteobacteria motility, but also fundamentals of the mechanics of the bacterial flagellar motor, and molecular evolution.

\section{Acknowledgements}

This work was supported by BBSRC grant BB/L023091/1.

\section{References}

[1] S. 1. w. On, Taxonomy of Campylobacter, Arcobacter, Helicobacter and related bacteria: current status, future prospects and immediate concerns, J. Appl. Microbiol. 90 (2001) 1S-15S.doi:10.1046/j.13652672.2001.01349.x.

[2] P. Lertsethtakarn, K.M. Ottemann, D.R. Hendrixson, Motility and Chemotaxis in Campylobacter and Helicobacter, Annu. Rev. Microbiol. 65 (2011) 389-410. doi:10.1146/annurev-micro-090110-102908.

[3] C. Baar, M. Eppinger, G. Raddatz, J. Simon, C. Lanz, O. Klimmek, et al., Complete genome sequence and analysis of Wolinellasuccinogenes, Proc. Natl. Acad. Sci. 100 (2003) 11690-11695. doi:10.1073/pnas.1932838100.

[4] J.A. Kiehlbauch, D.J. Brenner, M.A. Nicholson, C.N. Baker, C.M. Patton, A.G. Steigerwalt, et al., Campylobacter butzleri sp. nov.isolated from humans and animals with diarrheal illness., J. Clin. Microbiol. 29 (1991) 376-385.

[5] K. Hagymási, Z. Tulassay, Helicobacter pylori infection: New pathogenetic and clinical aspects, World J. Gastroenterol. WJG. 20 (2014) 6386-6399. doi:10.3748/wjg.v20.i21.6386.

[6] S.D.H. Malnick, E. Melzer, M. Attali, G. Duek, J. Yahav, Helicobacter pylori: Friend or foe?, World J. Gastroenterol. WJG. 20 (2014) 8979-8985. doi:10.3748/wjg.v20.i27.8979.

[7] B.J. Marshall, J.R. Warren, Unidentified curved bacilli in the stomach of patients with gastritis and peptic ulceration, Lancet. 1 (1984) 1311-1315. 
[8] C.A. Johnson-Delaney, The Ferret Gastrointestinal Tract and Helicobacter mustelae Infection, Veterinary Clin. North Am. Exot. Anim. Pract. 8 (2005) 197-212. doi:10.1016/j.cvex.2005.01.003.

[9] R.J. Cahill, C.J. Foltz, J.G. Fox, C.A. Dangler, F. Powrie, D.B. Schauer, Inflammatory bowel disease: an immunity-mediated condition triggered by bacterial infection with Helicobacterhepaticus., Infect. Immun. 65 (1997) 3126-3131.

[10]A. Curry, A.J. Fox, D.M. Jones, A New Bacterial Flagellar Structure Found in Campylobacters, J. Gen. Microbiol. 130 (1984) 1307-1310. doi:10.1099/00221287-130-5-1307.

[11]S. Nakagawa, Y. Takaki, S. Shimamura, A.-L. Reysenbach, K. Takai, K. Horikoshi, Deep-sea vent epsilon-proteobacterial genomes provide insights into emergence of pathogens, Proc. Natl. Acad. Sci. U. S. A. 104 (2007) 12146-12150. doi:10.1073/pnas.0700687104.

[12]M.T. Fera, T.L. Maugeri, C. Gugliandolo, C. Beninati, M. Giannone, E.L. Camera, et al., Detection of Arcobacter spp. in the Coastal Environment of the Mediterranean Sea, Appl. Environ. Microbiol. 70 (2004) 1271-1276. doi:10.1128/AEM.70.3.1271-1276.2004.

[13] J. Grote, T. Schott, C.G. Bruckner, F.O. Glöckner, G. Jost, H. Teeling, et al., Genome and physiology of a model Epsilonproteobacterium responsible for sulfide detoxification in marine oxygen depletion zones, Proc. Natl. Acad. Sci. 109 (2012) 506-510. doi:10.1073/pnas.1111262109.

[14]K. Takai, M. Suzuki, S. Nakagawa, M. Miyazaki, Y. Suzuki, F. Inagaki, et al., Sulfurimonasparalvinellae sp. nov., a novel mesophilic, hydrogen- and sulfur-oxidizing chemolithoautotroph within the Epsilonproteobacteria isolated from a deep-sea hydrothermal vent polychaete nest, reclassification of Thiomicrospiradenitrificans as Sulfurimonasdenitrificans comb. nov.and emended description of the genus Sulfurimonas, Int. J. Syst. Evol. Microbiol. 56 (2006) 17251733. doi:10.1099/ijs.0.64255-0.

[15] Y. Kodama, K. Watanabe, Sulfuricurvumkujiense gen. nov., sp. nov., a facultatively anaerobic, chemolithoautotrophic, sulfur-oxidizing bacterium isolated from an underground crude-oil storage cavity, Int. J. Syst. Evol. Microbiol. 54 (2004) 2297-2300. doi:10.1099/ijs.0.63243-0.

[16]C.R. McCLUNG, D.G. Patriquin, R.E. Davis, Campylobacter nitrofigilis sp. nov., a Nitrogen-Fixing Bacterium Associated with Roots of SpartinaalternifloraLoisel, Int. J. Syst. Bacteriol. 33 (1983) 605612. doi:10.1099/00207713-33-3-605.

[17]J. Sikorski, A. Lapidus, A. Copeland, T. Glavina Del Rio, M. Nolan, S. Lucas, et al., Complete genome sequence of Sulfurospirillumdeleyianum type strain (5175T), Stand. Genomic Sci. 2 (2010) 149-157. doi:10.4056/sigs.671209.

[18] Y. Suzuki, T. Sasaki, M. Suzuki, Y. Nogi, T. Miwa, K. Takai, et al., Novel Chemoautotrophic Endosymbiosis between a Member of the Epsilonproteobacteria and the Hydrothermal-Vent Gastropod Alviniconchaaff. hessleri (Gastropoda: Provannidae) from the Indian Ocean, Appl. Environ. Microbiol. 71 (2005) 5440-5450. doi:10.1128/AEM.71.9.5440-5450.2005.

[19] S.C. Cary, M.T. Cottrell, J.L. Stein, F. Camacho, D. Desbruyeres, Molecular Identification and Localization of Filamentous Symbiotic Bacteria Associated with the Hydrothermal Vent Annelid Alvinellapompejana, Appl. Environ. Microbiol. 63 (1997) 1124-1130.

[20]T. Urich, A. Lanzén, R. Stokke, R.B. Pedersen, C. Bayer, I.H. Thorseth, et al., Microbial community structure and functioning in marine sediments associated with diffuse hydrothermal venting assessed by integrated meta-omics, Environ. Microbiol. 16 (2014) 2699-2710. doi:10.1111/1462-2920.12283.

[21]T. Sterzenbach, L. Bartonickova, W. Behrens, B. Brenneke, J. Schulze, F. Kops, et al., Role of the Helicobacter hepaticusFlagellar Sigma Factor FliA in Gene Regulation and Murine Colonization, J. Bacteriol. 190 (2008) 6398-6408. doi:10.1128/JB.00626-08.

[22]T. Nakagawa, K. Takai, Y. Suzuki, H. Hirayama, U. Konno, U. Tsunogai, et al., Geomicrobiological exploration and characterization of a novel deep-sea hydrothermal system at the TOTO caldera in the Mariana Volcanic Arc, Environ. Microbiol. 8 (2006) 37-49. doi:10.1111/j.1462-2920.2005.00884.x.

[23] A.P. Petroff, X.-L. Wu, A. Libchaber, Fast-Moving Bacteria Self-Organize into Active TwoDimensional Crystals of Rotating Cells, Phys. Rev. Lett. 114 (2015) 158102.doi:10.1103/PhysRevLett.114.158102.

\section{** Petroff (2015): Microscopy study of the swimming behaviour of Thiovulum cells revealing complex emergent properties that are likely a result of the large cell size and swimming ability.}

[24]R.L. Ferrero, A. Lee, Motility of Campylobacter jejuni in a Viscous Environment: Comparison with Conventional Rod-Shaped Bacteria, J. Gen. Microbiol. 134 (1988) 53-59. doi:10.1099/00221287-134-1- 
53.

[25]T. Fenchel, Motility and chemosensory behaviour of the sulphur bacterium Thiovulummajus, Microbiology. 140 (1994) 3109-3116. doi:10.1099/13500872-140-11-3109.

[26] S.L. Hazell, A. Lee, L. Brady, W. Hennessy, Campylobacter pyloridis and Gastritis: Association with Intercellular Spaces and Adaptation to an Environment of Mucus as Important Factors in Colonization of the Gastric Epithelium, J. Infect. Dis. 153 (1986) 658-663.

[27]J.P. Celli, B.S. Turner, N.H. Afdhal, S. Keates, I. Ghiran, C.P. Kelly, et al., Helicobacter pylori moves through mucus by reducing mucin viscoelasticity, Proc. Natl. Acad. Sci. U. S. A. 106 (2009) 1432114326. doi:10.1073/pnas.0903438106.

[28] S.W. Reid, M.C. Leake, J.H. Chandler, C.-J. Lo, J.P. Armitage, R.M. Berry, The Maximum Number of Torque-Generating Units in the Flagellar Motor of Escherichia Coli Is at Least 11, Proc. Natl. Acad. Sci. 103 (2006) 8066-8071. doi:10.1073/pnas.0509932103.

[29] Y. Sowa, R.M. Berry, Bacterial Flagellar Motor, Q. Rev. Biophys. 41 (2008) 103-132. doi:10.1017/S0033583508004691.

[30]A. Lee, S.L. Hazell, J. O'Rourke, S. Kouprach, Isolation of a spiral-shaped bacterium from the cat stomach., Infect. Immun. 56 (1988) 2843-2850.

[31]M. Shigematsu, A. Umeda, S. Fujimoto, K. Amako, Spirochaete-Like Swimming Mode of Campylobacter Jejuni in a Viscous Environment, J. Med. Microbiol. 47 (1998) 521-526. doi:10.1099/00222615-47-6-521.

[32]L. Sycuro, Z. Pincus, K. Gutierrez, J. Biboy, C. Stern, W. Vollmer, et al., Peptidoglycan crosslinking relaxation promotes Helicobacter pylori's helical shape and stomach colonization., Cell. 141 (2010) 822-833.

[33]J.L. Smith, B.J. Campbell, T.E. Hanson, C.L. Zhang, S.C. Cary, Nautiliaprofundicola sp. nov., a thermophilic, sulfur-reducing epsilonproteobacterium from deep-sea hydrothermal vents, Int. J. Syst. Evol. Microbiol. 58 (2008) 1598-1602. doi:10.1099/ijs.0.65435-0.

[34]A. Lee, M.W. Phillips, J.L. O’rourke, B.J. Paster, F.E. Dewhirst, G.J. Fraser, et al., Helicobacter Muridarum Sp. Nov., a Microaerophilic Helical Bacterium with a Novel Ultrastructure Isolated from the Intestinal Mucosa of Rodents, Int. J. Syst. Bacteriol. 42 (1992) 27-36. doi:10.1099/00207713-42-1-27.

[35] S.B. Moura, E.N. Mendes, D.M.M. Queiroz, E.R.S. Camargos, M.E.F. Fonseca, G.A. Rocha, et al., Ultrastructure of Helicobacter Trogontum in Culture and in the Gastrointestinal Tract of Gnotobiotic Mice, J. Med. Microbiol. 47 (1998) 513-520. doi:10.1099/00222615-47-6-513.

[36]B.I. Kazmierczak, D.R. Hendrixson, Spatial and numerical regulation of flagellar biosynthesis in polarly flagellated bacteria, Mol. Microbiol. 88 (2013) 655-663. doi:10.1111/mmi.12221.

* Kazmierczak (2013): Concise review surveying the role of FlhF and FlhG in the polar flagellates.

[37]J. O'Rourke, A. Lee, J.G. Fox, An Ultrastructural Study of Helicobacter Mustelae and Evidence of a Specific Association with Gastric Mucosa, J. Med. Microbiol. 36 (1992) 420-427. doi:10.1099/00222615-36-6-420.

[38]W. de BOER, J.W. La Riviere, A.L. Houwink, Observations on the morphology of ThiovulummajusHinze, Antonie Van Leeuwenhoek. 27 (1961) 447-456.

[39] A. Müller, M. Beeby, A.W. McDowall, J. Chow, G.J. Jensen, W.M. Clemons, Ultrastructure and complex polar architecture of the human pathogen Campylobacter jejuni, MicrobiologyOpen. (2014) n/a-n/a. doi:10.1002/mbo3.200.

* Muller (2014): Electron cryo-tomography study of the ultrastructure of $C$. jejuni, revealing complex flagellar motor, ribosome-exclusion zone, and flagellar-proximal storage granules.

[40]S. Chen, M. Beeby, G.E. Murphy, J.R. Leadbetter, D.R. Hendrixson, A. Briegel, et al., Structural diversity of bacterial flagellar motors, EMBO J. 30 (2011) 2972-2981.doi:10.1038/emboj.2011.186.

[41]T. Minamino, K. Imada, K. Namba, Molecular motors of the bacterial flagella, Curr.Opin. Struct. Biol. 18 (2008) 693-701. doi:10.1016/j.sbi.2008.09.006.

[42] Y. Asai, I. Kawagishi, R.E. Sockett, M. Homma, Hybrid Motor with H+- and Na+-Driven Components Can Rotate Vibrio Polar Flagella by Using Sodium Ions, J. Bacteriol. 181 (1999) 6332-6338.

[43] V.E. Galkin, X. Yu, J. Bielnicki, J. Heuser, C.P. Ewing, P. Guerry, et al., Divergence of Quaternary Structures Among Bacterial Flagellar Filaments, Science. 320 (2008) 382-385. 
doi:10.1126/science.1155307.

[44] A.E. Ritchie, R.F. Keeler, J.H. Bryner, Anatomical Features of Vibrio Fetus: Electron Microscopic Survey, J. Gen. Microbiol. 43 (1966) 427-438. doi:10.1099/00221287-43-3-427.

[45]C.-H. Lai, M.A. Listgarten, A.C.R. Tanner, S.S. Socransky, Ultrastructures of BacteroidesGracilis, Campylobacter Concisus, Wolinella Recta, and EikenellaCorrodens, All from Humans with Periodontal Disease, Int. J. Syst. Bacteriol. 31 (1981) 465-475. doi:10.1099/00207713-31-4-465.

[46]J. Kupper, I. Wildhaber, Z. Gao, E. Baeuerlein, Basal-Body-Associated Disks Are Additional Structural Elements of the Flagellar Apparatus Isolated from WolinellaSuccinogenes., J. Bacteriol. 171 (1989) 2803-2810.

[47]C.O. Wirsen, S.M. Sievert, C.M. Cavanaugh, S.J. Molyneaux, A. Ahmad, L.T. Taylor, et al., Characterization of an Autotrophic Sulfide-Oxidizing Marine Arcobacter sp. That Produces Filamentous Sulfur, Appl. Environ.Microbiol. 68 (2002) 316-325. doi:10.1128/AEM.68.1.316-325.2002.

[48] S.C. Schuster, E. Baeuerlein, Location of the Basal Disk and a Ringlike Cytoplasmic Structure, Two Additional Structures of the Flagellar Apparatus of WolinellaSuccinogenes., J. Bacteriol. 174 (1992) 263-268.

[49]F.G. Ferris, T.J. Beveridge, M.L. Marceau-Day, A.D. Larson, Structure and cell envelope associations of flagellar basal complexes of Vibrio cholerae and Campylobacter fetus, Can. J. Microbiol. 30 (1984) 322-333.

[50]T. Yamamoto, T. Takano, W. Higuchi, W.-C. Hung, I. Reva, S. Yabe, et al., Unique features of the motility and structures in the flagellate polar region of Campylobacter jejuni and other species: an electron microscopic study, Microbiol. Immunol. 57 (2013) 83-90. doi:10.1111/1348-0421.12013.

[51]M. Beeby, D.A. Ribardo, C.A. Brennan, E.G. Ruby, G.J. Jensen, D.R. Hendrixson, Diverse high-torque bacterial flagellar motors assemble wider stator rings using a conserved protein scaffold, Prep. (n.d.).

\section{** Beeby (2015): Identification of novel components of the epsilon-proteobacteria and demonstration of their location in the motor by electron cryo-tomography.}

[52]C.F. Reboul, D.A. Andrews, M.F. Nahar, A.M. Buckle, A. Roujeinikova, Crystallographic and Molecular Dynamics Analysis of Loop Motions Unmasking the Peptidoglycan-Binding Site in Stator Protein MotB of Flagellar Motor, PloS One. 6 (2011) e18981.doi:10.1371/journal.pone.0018981.

[53] Y. Hizukuri, S. Kojima, M. Homma, Disulphide cross-linking between the stator and the bearing components in the bacterial flagellar motor, J. Biochem. (Tokyo). 148 (2010) 309-318. doi:10.1093/jb/mvq067.

[54]S. Khan, M. Dapice, T.S. Reese, Effects of mot gene expression on the structure of the flagellar motor, J. Mol. Biol. 202 (1988) 575-584.doi:10.1016/0022-2836(88)90287-2.

[55]B. Gao, M. Lara-Tejero, M. Lefebre, A.L. Goodman, J.E. Galán, Novel Components of the Flagellar System in Epsilonproteobacteria, mBio. 5 (2014) e01349-14.doi:10.1128/mBio.01349-14.

\section{** Gao (2014): Identification of putative novel components of the epsilon-proteobacteriaflagellar motor by high-throughput transposon screening.}

[56] S.M. Sommerlad, D.R. Hendrixson, Analysis of the roles of FlgP and FlgQ in flagellar motility of Campylobacter jejuni, J. Bacteriol. 189 (2007) 179-186. doi:10.1128/JB.01199-06.

[57]C.R.J. Hubert, T.B.P. Oldenburg, M. Fustic, N.D. Gray, S.R. Larter, K. Penn, et al., Massive dominance of Epsilonproteobacteria in formation waters from a Canadian oil sands reservoir containing severely biodegraded oil, Environ. Microbiol. 14 (2012) 387-404. doi:10.1111/j.1462-2920.2011.02521.x.

[58] Y. Kodama, K. Watanabe, Isolation and Characterization of a Sulfur-Oxidizing Chemolithotroph Growing on Crude Oil under Anaerobic Conditions, Appl. Environ. Microbiol. 69 (2003) 107-112. doi:10.1128/AEM.69.1.107-112.2003.

[59] K. Meyer-Rosberg, D.R. Scott, D. Rex, K. Melchers, G. Sachs, The effect of environmental pH on the proton motive force of Helicobacter pylori, Gastroenterology. 111 (1996) 886-900. doi:10.1016/S00165085(96)70056-2. 


\section{Figure legends}

190 Figure 1: An overview of epsilon-proteobacterial cell plan and motility. Notes on motility are described

191 where known. References are listed in Bibliography.

192 Figure 2: Imaging the epsilon-proteobacterialflagellar motor. (a) TEM images of epsilon-

193 proteobacterialflagellar motors for H. mustelae[37], C. coli [50], C. fetus(left) [49], (right) [50], (b) freeze-

194 fracture images reveal 17 'studs' likely to be stator complexes in H. felis[30]and H. muridarium[34]. (c)

195 computational slices through subtomogram averages of $S$. enterica(for comparison), H. hepaticus, and $C$.

196 jejuni [40,51]. Cross-section of $C$. jejuni motor is through plane designated by white dashes. Boxes in panel

197 (c) are 100nm x 100nm. (d) schematic highlighting the differences between the Salmonella and $C$.

198 jejuniflagellar motor, with novel epsilon-proteobacteria components labelled [51]. 
Highlights for Beeby, "Motility in the epsilon-proteobacteria”

- Epsilon-proteobacteria inhabit animal digestive tracts or environmental niches.

- Characteristic of the group is distinctive rapid motility even at high viscosities.

- Motility is achieved by polar flagella considerably more complex than model systems.

- Studies are now identifying novel components of these complex flagella.

- Evidence suggests that motor complexity may contribute to high swimming torque. 


\section{Imperial College London}

$28^{\text {th }}$ August 2015
Department of Life Sciences

Imperial College London

Room 502, Sir Ernst Chain Building

South Kensington Campus

Imperial College London, SW7 2AZ

Tel: +44 (0)20 75945251

mbeeby@imperial.ac.uk

www.imperial.ac.uk/people/m.beeby

Morgan Beeby, PhD

Lecturer in Structural Biology

Dear Editors,

Please find attached a resubmitted manuscript for the special edition of Current Opinion in Microbiology titled "Growth and Development: Eukaryotes / Prokaryotes".

Please note that the manuscript makes reference to unpublished work from my lab that I plan to have published by the time of this review. The review may need minor alteration to reflect this.

Yours sincerely,

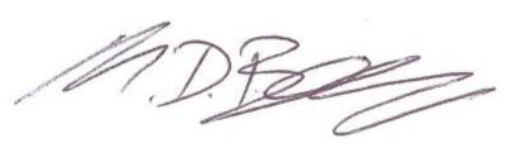

Morgan Beeby

Imperial College London, UK 


\section{Figure 1}

\begin{tabular}{l|l} 
Salt marsh & Swims with rapid corkscrew McClung
\end{tabular}

sediments motion

(1983)

associated with

plant roots

Gastrointestinal Rapid darting motility

Kiehlbauch

pathogen

(1991)

butzleri

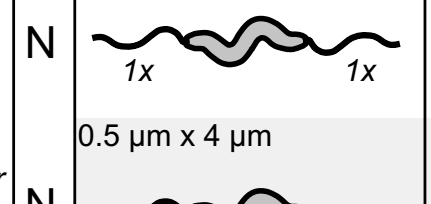

Campylobacter

$\mathrm{N}$

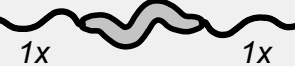

Gastrointestinal

Swims with rapid corkscrew

Ferrero (1988)

pathogen;

motion. Ability to swim

commensal of birds

through viscous media.

Gastrointestinal

pathogen;

Campylobacter

$0.5 \mu \mathrm{m} \times 4 \mu \mathrm{m}$

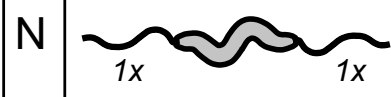

commensal of birds

Yamamoto

(2012)

Reproductive tract

Ferris (1984)

pathogen in

animals

fetus

Sulfurospirillum deleyianum

$N$
$N$



$0.3-0.5 \mu \mathrm{m} \times 1-3 \mu \mathrm{m}$

Anoxic mud from a

forest pond in

Germany

Cat intestine

$0.4 \mu \mathrm{m} \times 5-7 \mu \mathrm{m}$

Helicobacter

felis

Y

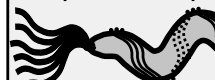

$10-17 x$

$0.2-0.3 \mu \mathrm{m} \times 1.5-5 \mu \mathrm{m}$

Helicobacter

hepaticus



Sulfurimonas

gotlandica

Sulfuricurvum

kujiense

Thiovulum

majus

Wolinella

succinogenes

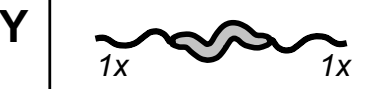

Livers of mice with

chronic hepatitus.

$0.5 \mu \mathrm{m} \times 2 \mu \mathrm{m}$



Natural inhabitant of ferret stomach.

Frequently seen

intracellularly.

$0.5 \mu \mathrm{m} \times 2.5-5 \mu \mathrm{m}$

Animal gastro-

intestinal tracts,

causing gastritis.

Often asymptomatic

Mud from marine

tidal flats in The

Netherlands

Underground

crude-oil storage

facility in Japan

Black mud from

marsh

N

$9-17 \mu \mathrm{m}$

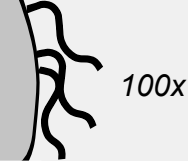

$0.5-1 \mu \mathrm{m} \times 2-6 \mu \mathrm{m}$

N

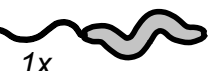

$0.3 \mu \mathrm{m} \times 0.4 \mu \mathrm{m}$

Nautilia

profundicola

$\mathrm{N}$

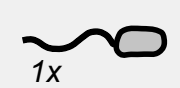

$0.8 \mu \mathrm{m} \times 2.5 \mu \mathrm{m}$

Nitratiruptor

tergacus

Salmonella

enterica;

Escherichia coll

Bovine

gastrointestina

tract

Deep-sea

hydrothermal vent

episymbiont of a

polychaete worm

Mid-Okinawa

Trough, Japan

Varied;

gastrointestinal
Human pathogen?

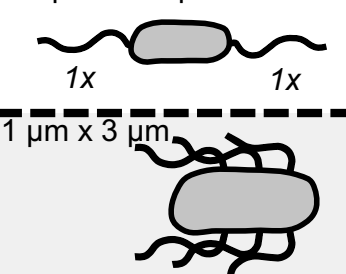

Hydrothermal field, Flagellated but

non-motile under

culture conditions

Sikorski

(2010)

Rapid corkscrew motility in Lee (1988)

mucous; also 'drilling' action

between and into tissue

cells.

Unusual spinning motility O'Rourke

due to rod shape and lateral (1992)

flagella? Superior swimming

in viscous media to $E$. coli.

High torque and swimming

activity. $3500 \mathrm{pN} \mathrm{nm}$

Marshall

(1985)

estimated swimming torque.

Grote (2012)

Capable of swimming at

$-600 \mu \mathrm{m} /$ second. Very

many peritrichous flagella.

Rapid, darting high motility

"Normal" models for

flagellated motility;

estimated $1260 \mathrm{pN} \mathrm{nm}$

swimming torque.
Petroff (2015)

Baar (2003)

Smith (2008)

Kodama (2004)

Nakagawa

(2007)

Minamino

(2008),

Sowa (2008) 


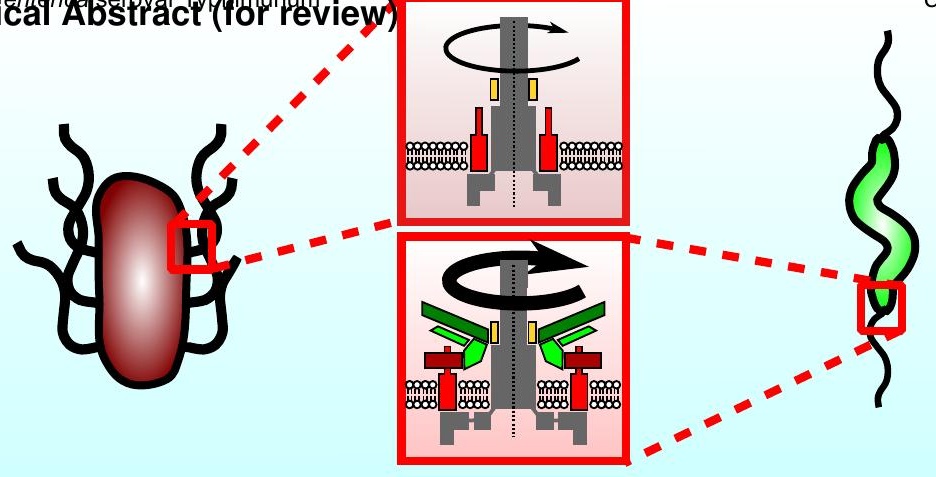

Campylobacter jejuni

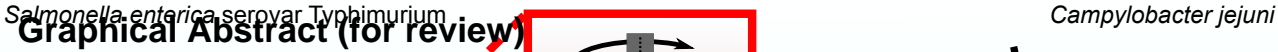




\section{Imperial College} London

$28^{\text {th }}$ August 2015
Department of Life Sciences

Imperial College London

Room 502, Sir Ernst Chain Building

South Kensington Campus

Imperial College London, SW7 2AZ

Tel: +44 (0)207594 5251

mbeeby@imperial.ac.uk

www.imperial.ac.uk/people/m.beeby

Morgan Beeby, PhD

Lecturer in Structural Biology

Dear Editors,

Because responses to reviews were extremely minor I have made the requested alterations to the text to enhance clarity, but do not include here any specific responses to points raised.

Yours sincerely,

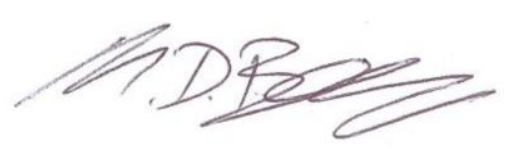

Morgan Beeby

Imperial College London, UK 